\title{
Identifying areas of emphasis for future palliative radiation therapy curricula via an examination of theMednet
}

\author{
Kunal K. Sindhu, Eric J. Lehrer, Kavita V. Dharmarajan \\ Department of Radiation Oncology, Icahn School of Medicine at Mount Sinai, New York, NY, USA \\ Contributions: (I) Conception and design: KK Sindhu; (II) Administrative support: KK Sindhu, EJ Lehrer; (III) Provision of study materials or \\ patients: KK Sindhu, EJ Lehrer; (IV) Collection and assembly of data: All authors; (V) Data analysis and interpretation: All authors; (VI) Manuscript \\ writing: All authors; (VII) Final approval of manuscript: All authors. \\ Correspondence to: Kunal K. Sindhu, MD. Department of Radiation Oncology, Icahn School of Medicine at Mount Sinai, 1184 Fifth Avenue, New \\ York, NY 10029, USA. Email: kunal.sindhu@mountsinai.org.
}

\begin{abstract}
Background: Palliative radiation therapy is essential to the care of patients with advanced cancer. Unfortunately, despite their benefits, the principles of palliative radiation therapy and palliative and supportive care are underrepresented in radiation oncology residency curricula. In this study, we attempted to identify areas of emphasis for future palliative radiation therapy curricula by examining the relevant questions posted to theMednet.

Methods: Questions tagged with both "Palliation" and "Radiation Oncology" or "General Radiation Oncology" that were posted to theMednet on or before January 7, 2020 were included in this analysis. The questions were grouped thematically, and subthemes within each broader thematic group were identified. Among the thematic groups, variations in social engagement metrics were assessed using the Kruskal-Wallis Test and non-parametric analysis of variance.
\end{abstract}

Results: A total of 4,188 questions tagged with the terms "Radiation Oncology," "General Radiation Oncology," or "Palliation" and posed between 2012 and 2020 were identified. Of these, 161 questions satisfied our inclusion criteria. Upon examination of the identified questions, eight thematic groups and several subthemes were identified, representing areas of possible emphasis for future palliative radiation therapy curricula. Among questions in different thematic groups, however, there were no statistically significant differences in any of the examined social engagement metrics.

Conclusions: We found many common question themes and subthemes in our examination of the palliative radiation oncology questions posted to theMednet. Our findings suggest that several opportunities for education exist for radiation oncology residents in regards to palliative and supportive care and palliative radiation therapy.

Keywords: Education; palliative radiation therapy; radiation oncology

Submitted Apr 20, 2021. Accepted for publication Jun 11, 2021.

doi: 10.21037/apm-21-956

View this article at: https://dx.doi.org/10.21037/apm-21-956

\section{Introduction}

Palliative radiation therapy is essential to the care of patients with advanced cancer. In the United States, in fact, it is widely used to provide symptom relief in patients with incurable or metastatic cancer. Roughly one-third of patients seen in radiation oncology clinics for consultation are referred for palliative treatment, and nearly 500,000 American adults
65 years of age and above receive palliative radiation therapy each year. Palliative radiation therapy is highly effective, yielding symptomatic relief in $60-80 \%$ of patients within 4-6 weeks (1-7). It also leads to improvements in quality of life and function (8-11).

Unfortunately, despite their benefits, the principles of palliative radiation therapy and palliative and supportive 
care are underrepresented in radiation oncology residency curricula. In fact, $15 \%$ of radiation oncology residency programs in the United States lacked a formal palliative radiation therapy curriculum and $33 \%$ lacked a formal palliative medicine and supportive care curriculum, according to the results of a 2017 survey sent to US radiation oncology residency program directors (12). Given the frequency with which radiation oncologists manage patients with advanced or incurable cancer, these gaps are concerning. Modifications to residency curricula in regards to palliative and supportive care in radiation oncology are needed.

theMednet is an online social network of physicians, the goal of which is "to facilitate dialogue among physicians on common clinical questions and practice patterns" (13). It is "an up to date knowledge base of clinical best practices for situations that are not clearly addressed by guidelines, published literature, and in textbooks" in which "expert analyses of evidence-based information and experiential insigbts" are conveyed through a question-and-answer format (14). As of February 2019, theMednet consisted of "over 13,000 medical, radiation, gynecological, and pediatric oncologists, rheumatologists, and bematologists", $60 \%$ of whom were community oncologists, $25 \%$ academics, and $15 \%$ residents and fellows (15).

In recent years, theMednet has been utilized to share discussions from tumor boards, relay experiential knowledge, and disseminate treatment strategies among clinicians during the COVID-19 pandemic (16-18). Utilization of theMednet is widespread among radiation oncologists; in fact, thousands of them have used it to obtain answers to questions regarding clinical management (19). In this study, we attempted to identify areas of emphasis for future palliative radiation therapy curricula by examining relevant questions posted to theMednet. We present the following article in accordance with the MDAR reporting checklist (available at https://dx.doi.org/10.21037/apm-21-956).

\section{Methods}

Questions tagged with "Radiation Oncology", "General Radiation Oncology", and "Palliation" that were posted to theMednet on or before January 7, 2020 were examined. To select for palliative radiation oncology questions specifically, only questions that were tagged with both "Palliation" and either "Radiation Oncology" or "General Radiation Oncology" were included in this analysis. The questions were grouped thematically, and subthemes within each broader thematic group were identified. Social engagement metrics, including the number of views each question had, the number of times it was identified as a "good question", the number of answers provided by members of the Mednet community, and the responses provided to any answers were recorded.

\section{Statistical analysis}

Among the thematic groups, variations in social engagement metrics were assessed using the Kruskal-Wallis Test and non-parametric analysis of variance. All statistical tests were two-sided, and the null hypothesis was rejected for $\mathrm{P}<0.05$. This study was deemed exempt by the Mount Sinai Institutional Review Board.

\section{Results}

A total of 4,188 questions tagged with the terms "Radiation Oncology", "General Radiation Oncology", or "Palliation" and posed between 2012 and 2020 were identified. Of these, 161 questions satisfied our inclusion criteria. The majority of questions were posted without attribution (96 questions, $60 \%)$; the remaining questions were posed by practicing radiation oncologists (45 questions, $28 \%$ ), residents (17 questions, $11 \%$ ), and fellows (3 questions, $2 \%$ ). One hundred and thirty-nine questions $(86 \%)$ were answered by a member of theMednet community, the vast majority (133/139) of which were answered between 2014 and 2019. The remaining six questions were answered in 2012, 2013, or 2020.

We identified seven broad thematic groups in our analysis of these questions. Forty-two questions (26\%) focused on the decision of whether to offer treatment in a particular clinical scenario, while 36 questions (22\%) pertained to technical questions regarding treatment planning, $26(16 \%)$ to appropriate radiation dosing and treatment duration, and $19(12 \%)$ to treatment logistics (for example, when to hold systemic therapy or begin radiation therapy). Additionally, 10 questions (6\%) were devoted to supportive care, 8 questions (5\%) asked about patient counseling, and 7 questions (4\%) inquired about the pre-radiation therapy work-up. Thirteen questions (8\%) that not fit into these seven categories were instead grouped together as an eighth thematic group (Table 1).

Considered as a whole, the examined questions garnered 497.7 views (median: 264, range, 7-4,657) and 1.7 answers (median: 1, range, $0-10$ ) on average. They were marked as "good question[s]" on average 2.2 times (median: 1, 
Table 1 Examples of palliative radiation oncology questions posted to theMednet

\begin{tabular}{ll}
\hline $\begin{array}{l}\text { Question } \\
\text { theme }\end{array}$ & $\begin{array}{l}\text { Question } \\
\text { subtheme }\end{array}$ \\
\hline $\begin{array}{l}\text { All questions } \\
\text { Decision to treat a } \\
\text { patient with radiation } \\
\text { therapy }\end{array}$ & \\
& \\
& $\begin{array}{l}\text { Would you treat with radiation } \\
\text { therapy in a particular clinical } \\
\text { scenario? } \\
\\
\end{array}$ \\
& $\begin{array}{l}\text { Would you treat with radiation } \\
\text { therapy in a particular clinical } \\
\text { scenario involving re-irradiation? } \\
\end{array}$ \\
& Other
\end{tabular}

Technical questions regarding treatment planning

Treatment technique

Dose constraints

Treatment volumes

Other

Dosing and treatment duration

What dose would you give?

Criteria/thought process on selecting dose

Other

Treatment logistics

When to hold systemic therapy

When to initiate radiation therapy

Other
Number of Examples of

questions posted questions
161

42

37 "Would you offer palliative radiation therapy for bleeding risk reduction in a patient with large vessel invasion from an intrathoracic tumor who requires anticoagulation?"

3 "Can a second course of SRS be used to treat a brain met that initially responded to SRS and then progressed?"

2

"Is there a role for Radium-223 in patients that have a non-prostate malignancy who otherwise would be a reasonable candidate?"

36

"What is the best radiation therapy treatment for vertebral body metastasis with epidural extension adjacent to the spinal cord for radio-resistant tumors (melanoma, renal cell, etc.)?"

7 "Are there any volumetric constraints associated with toxicity in the dose range that is moderately above prescription (i.e., 30-35 Gy range), when planning hippocampal-sparing whole brain radiation?"

5

"Is it necessary to treat one vertebral body above and below for palliation of spinal metastases?"

5 "What MRI sequences do you utilize for spine SRS treatment planning?"

26

"What is a safe and effective dose and fractionation for palliating head and neck cancer?"

4 "How do you decide on a fractionation scheme for retreatment of a progressive/painful spine metastasis?"

1 "Is it safe to use doses of 3 Gy in a BID treatment for palliative urgent cases?"

19

9 "Do you routinely hold immunotherapy during whole brain radiation?"

$5 \quad$ "How long would you wait after a patient receives intrathecal [methotrexate] for DLBCL prior to treating a painful spine metastasis without cord compression?"

5 "How are patients on anticoagulation managed in the context of intracranial SRS?"

Table 1 (continued) 
Table 1 (continued)

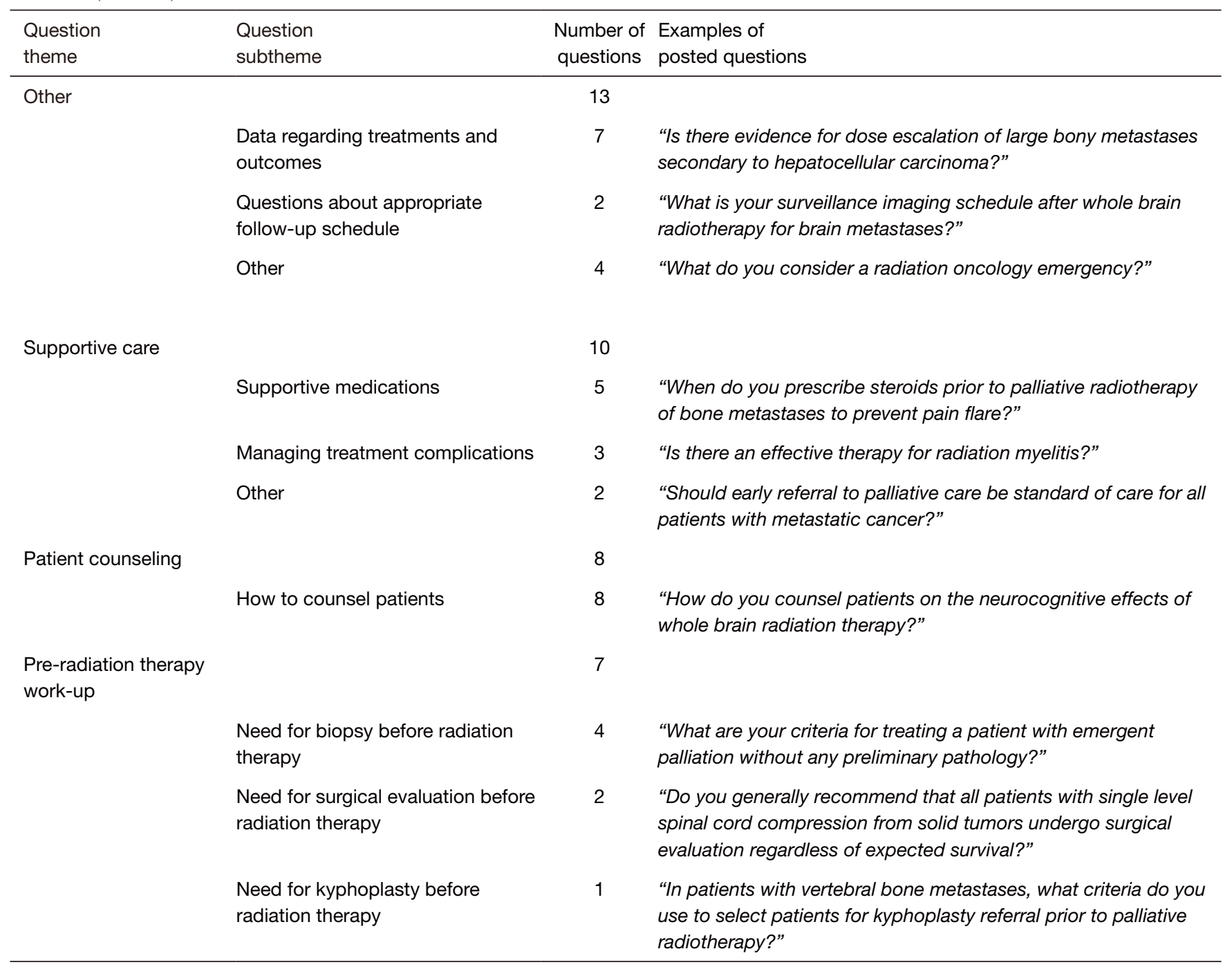

SRS, stereotactic radiosurgery; MRI, mgnetic resonance imaging; DLBCL, diffuse large B-cell lymphoma.

range, 0-29). In addition, the answers to the questions in this study received 0.4 comments on average (median: 0 , range $0-7$ ). Of the eight broad thematic question groups we identified, questions about dosing and treatment duration had the most views (702.5 on average; range, 154.6-702.5 for thematic question groups) and answers (2.1 on average; range 1.0-2.1). In contrast, questions about "Patient counseling" (8 questions) and "Pre-radiation therapy workup" (7 questions) had the fewest number of average views (208.4 and 154.6 views, respectively). Questions pertaining to treatment logistics were most frequently marked as "good question[s]" (2.9 times on average; range, 0.6-2.9), while the answers to questions about whether to treat a patient received the most comments ( 0.8 on average; range, $0-0.8$ ) (Table 2). However, there were no statistically significant differences in any of the examined social engagement metrics among questions in different thematic groups $(\mathrm{P}>0.05)$.

Additionally, a number of subthemes were noted within each thematic group. Ninety-five percent of questions pertaining to the decision to offer treatment to a patient, for example, asked members of theMednet community if they would treat a patient in a particular clinical scenario, including $7 \%$ pertaining to cases involving the possibility of re-irradiation. Fifty-three percent of questions pertaining to treatment planning asked about treatment techniques, 
Table 2 Palliative radiation oncology questions posted to theMednet-metrics

\begin{tabular}{|c|c|c|c|c|c|c|}
\hline Question theme & Question subtheme & $\begin{array}{l}\text { Number of } \\
\text { questions }\end{array}$ & \multicolumn{4}{|c|}{ Average number } \\
\hline \multirow{4}{*}{$\begin{array}{l}\text { Decision to treat a } \\
\text { patient with radiation } \\
\text { therapy }\end{array}$} & & 42 & 593.4 & 2.4 & 1.8 & 0.8 \\
\hline & $\begin{array}{l}\text { Would you treat with radiation therapy in } \\
\text { a particular clinical scenario? }\end{array}$ & 37 & 633.3 & 2.6 & 1.9 & 0.8 \\
\hline & $\begin{array}{l}\text { Would you treat with radiation therapy in } \\
\text { a particular clinical scenario involving } \\
\text { re-irradiation? }\end{array}$ & 3 & 436.7 & 1.3 & 1.7 & 1.3 \\
\hline & Other & 2 & 90.0 & 0.0 & 0.5 & 0.0 \\
\hline \multirow{5}{*}{$\begin{array}{l}\text { Technical questions } \\
\text { regarding treatment } \\
\text { planning }\end{array}$} & & 36 & 416.8 & 1.9 & 1.5 & 0.3 \\
\hline & Treatment technique & 19 & 396.3 & 1.9 & 1.6 & 0.5 \\
\hline & Dose constraints & 7 & 539.1 & 1.7 & 1.4 & 0.0 \\
\hline & Treatment volumes & 5 & 383.4 & 1.6 & 1.4 & 0.0 \\
\hline & Other & 5 & 357.0 & 2.2 & 1.6 & 0.6 \\
\hline \multirow{4}{*}{$\begin{array}{l}\text { Dosing and treatment } \\
\text { duration }\end{array}$} & & 26 & 702.5 & 2.3 & 2.1 & 0.5 \\
\hline & What dose would you give? & 21 & 710.3 & 2.4 & 2.2 & 0.6 \\
\hline & $\begin{array}{l}\text { Criteria/thought process on selecting } \\
\text { dose }\end{array}$ & 4 & 814.0 & 2.5 & 1.8 & 0.3 \\
\hline & Other & 1 & 590.0 & 1.0 & 2.0 & 0.0 \\
\hline \multirow[t]{4}{*}{ Treatment logistics } & & 19 & 500.8 & 2.9 & 1.5 & 0.3 \\
\hline & When to hold systemic therapy & 9 & 628.8 & 4.6 & 1.4 & 0.7 \\
\hline & When to initiate radiation therapy & 5 & 192.2 & 1.4 & 1.0 & 0.0 \\
\hline & Other & 5 & 579.2 & 1.6 & 2.0 & 0.0 \\
\hline \multirow[t]{4}{*}{ Other } & & 13 & 402.5 & 1.9 & 1.5 & 0.2 \\
\hline & Data regarding treatments and outcomes & 7 & 525.6 & 3.0 & 1.7 & 0.4 \\
\hline & $\begin{array}{l}\text { Questions about appropriate follow-up } \\
\text { schedule }\end{array}$ & 2 & 479.5 & 0.0 & 1.5 & 0.0 \\
\hline & Other & 4 & 148.8 & 1.0 & 1.0 & 0.0 \\
\hline \multirow[t]{4}{*}{ Supportive care } & & 10 & 443.8 & 2.6 & 1.9 & 0.3 \\
\hline & Supportive medications & 5 & 590.0 & 3.6 & 2.4 & 0.0 \\
\hline & Managing treatment complications & 3 & 335.0 & 2.7 & 1.7 & 0.7 \\
\hline & Other & 2 & 241.5 & 0.0 & 1.0 & 0.5 \\
\hline
\end{tabular}

Table 2 (continued) 
Table 2 (continued)

\begin{tabular}{|c|c|c|c|c|c|c|}
\hline Question theme & Question subtheme & $\begin{array}{l}\text { Number of } \\
\text { questions }\end{array}$ & \multicolumn{4}{|c|}{ Average number } \\
\hline Patient counseling & How to counsel patients & 8 & 208.4 & 1.0 & 1.1 & 0.0 \\
\hline \multirow{3}{*}{$\begin{array}{l}\text { Pre-radiation therapy } \\
\text { work-up }\end{array}$} & Need for biopsy before radiation therapy & 4 & 140.3 & 0.5 & 1.3 & 0.0 \\
\hline & $\begin{array}{l}\text { Need for surgical evaluation before } \\
\text { radiation therapy }\end{array}$ & 2 & 99.0 & 0.5 & 0.5 & 0.0 \\
\hline & $\begin{array}{l}\text { Need for kyphoplasty before radiation } \\
\text { therapy }\end{array}$ & 1 & 323.0 & 1.0 & 1.0 & 0.0 \\
\hline
\end{tabular}

$19 \%$ about dose constraints, and 14\% about treatment volumes. Lastly, among questions about dose regimens, $81 \%$ asked members of the theMednet community about the prescription dose they would deliver in a particular clinical scenario.

\section{Discussion}

Most radiation oncology residency program directors agree that obtaining proficiency in palliative and supportive care and palliative radiation therapy is an important aspect of radiation oncology residency training. However, significant gaps exist in radiation oncology residency curricula in regards to these competencies. In the United States, in addition to the significant number of radiation oncology residency programs that do not have any formal palliative radiation therapy and palliative and supportive care curricula, $65 \%$ of surveyed programs reported lacking a designated faculty member responsible for educating residents on these topics. Moreover, of the 19\% of US radiation oncology residency programs that reported having a dedicated palliative radiation therapy service, only $56 \%$ had residents rotating on that service (12).

The recurring themes we identified in the questions posted to theMednet suggest that significant opportunities for education among radiation oncologists regarding the delivery of palliative radiation therapy exist. Seventysix percent of the questions identified in this analysis, for example, pertained to 1 of 4 critical areas of palliative radiation oncology: the decision to offer treatment to a patient, treatment planning, dose regimens, and treatment logistics. When different subthemes were examined, we found that $50 \%$ of the questions in this analysis related to one of just three topics: whether to offer treatment to a patient in a particular clinical scenario, the dose regimen members of theMednet community would recommend in a particular clinical scenario, and dose constraints. These findings suggest potential topics for residency curricula to emphasize nationwide. On the basis of this study's findings, for example, palliative radiation therapy curricula should, at the minimum, outline the clinical scenarios in which it is appropriate to offer palliative radiation therapy to patients; discuss the efficacy of palliative radiation therapy in alleviating various symptoms experienced by patients with cancer; explore the pros and cons of selecting particular radiation therapy techniques and dose regimens when delivering palliative radiation therapy; define dose constraints for various organs at risk throughout the body; explain how target delineation differs when treating a patient with either definitive and palliative radiation therapy; and review when to initiate radiation therapy and hold systemic therapy. To ensure that these topics are covered during residency, the addition of a palliative component to the board certification process should also be considered.

Of course, there are inherent limitations in attempting to glean knowledge gaps among an entire cohort of practicing radiation oncologists and identifying areas of emphasis for future palliative radiation therapy and palliative and supportive care curricula by examining voluntary posts to a social network. A study of this nature is inherently prone to self-selection bias, as individual actors choose whether or 
not to post their queries to the social network of interest. Thus, it is unclear whether the questions posed by various clinicians are reflective of the uncertainties of radiation oncologists as a whole. Additionally, it is possible that our inclusion criteria, requiring that questions be tagged with both "Palliation" and either "Radiation Oncology" or "General Radiation Oncology", may have missed representative questions posed by clinicians that were not accurately tagged and thus resulted in findings that inadequately describe the knowledge gaps of practicing radiation oncologists. Thirdly, given that a significant fraction of questions could not be attributed to an individual at a particular level of training, it is not possible to clarify if the knowledge gaps identified in this study are particularly acute among radiation oncology residents, fellows, and/ or attendings. Lastly, given the relatively small sample size of questions included in this study, it is possible that our results inappropriately overrepresented some topics and underrepresented others.

It should be noted that prior studies have identified significant knowledge gaps related to the delivery of palliative and supportive care among practicing radiation oncologists. A 2003 survey with over 600 respondents who were members of the American Society for Radiation Oncology, for example, found that approximately $40 \%$ "thought that their residency program did only a fair or poor job in preparing them for pain and symptom management and communication with patients and families" and $73.2 \%$ "felt ill prepared to deal with end-of-life needs" (20). Additionally, a 2017 survey found that large proportions of practicing US radiation oncologists lacked confidence in their ability to manage some common symptoms experienced by patients with cancer. Majorities, in fact, did not have confidence in their ability to manage anorexia, anxiety, depression, fatigue, and insomnia. Additionally, less than $60 \%$ had confidence in their ability to navigate several common clinical scenarios faced by patients at the end of their lives (21). Unfortunately, there is limited survey data exploring the knowledge gaps of practicing radiation oncologists when it comes to the delivery of palliative radiation therapy. Thus, further studies surveying their views would be necessary to validate our results.

However, our findings, when combined with the lack of confidence practicing radiation oncologists report in managing common symptoms and scenarios experienced by patients with cancer, strongly suggest that an expanded role for palliative and supportive care in radiation oncology residency curricula is warranted.
In sum, our analysis of the palliative radiation oncology questions posted to theMednet identified numerous common question themes and subthemes. Our findings suggest that several opportunities for education exist for radiation oncology residents in regards to palliative and supportive care and palliative radiation therapy. An expanded role for palliative and supportive care education in radiation oncology residency curricula may assist in reducing future clinical uncertainties.

\section{Acknowledgments}

Data from this project was presented in abstract form at the 2020 American Society for Radiation Oncology Annual Meeting (October 25-28, 2020).

Funding: None.

\section{Footnote}

Reporting Checklist: The authors have completed the MDAR reporting checklist. Available at https://dx.doi. org/10.21037/apm-21-956

Data Sharing Statement: Available at https://dx.doi. org/10.21037/apm-21-956

Peer Review File: Available at https://dx.doi.org/10.21037/ apm-21-956

Conflicts of Interest: All authors have completed the ICMJE uniform disclosure form (available at https://dx.doi. org/10.21037/apm-21-956). The authors have no conflicts of interest to declare.

Ethical Statement: The authors are accountable for all aspects of the work in ensuring that questions related to the accuracy or integrity of any part of the work are appropriately investigated and resolved. This study was deemed exempt by the Mount Sinai Institutional Review Board.

Open Access Statement: This is an Open Access article distributed in accordance with the Creative Commons Attribution-NonCommercial-NoDerivs 4.0 International License (CC BY-NC-ND 4.0), which permits the noncommercial replication and distribution of the article with the strict proviso that no changes or edits are made and the original work is properly cited (including links to both the 
formal publication through the relevant DOI and the license). See: https://creativecommons.org/licenses/by-nc-nd/4.0/.

\section{References}

1. Mariotto AB, Yabroff KR, Shao Y, et al. Projections of the cost of cancer care in the United States: 2010-2020. J Natl Cancer Inst 2011;103:117-28.

2. Bryant AK, Banegas MP, Martinez ME, et al. Trends in Radiation Therapy among Cancer Survivors in the United States, 2000-2030. Cancer Epidemiol Biomarkers Prev 2017;26:963-70.

3. Jones JA, Lutz ST, Chow E, et al. Palliative radiotherapy at the end of life: a critical review. CA Cancer J Clin 2014;64:296-310.

4. Murphy JD, Nelson LM, Chang DT, et al. Patterns of care in palliative radiotherapy: a population-based study. J Oncol Pract 2013;9:e220-7.

5. Sindhu KK, Chang S, Liu J, et al. In a Patient With Cancer, Not All That Enhances Is Leptomeningeal Carcinomatosis. J Oncol Pract 2019;15:558-9.

6. Sindhu K, Syed S, Cielo D. The Role of Radiation Therapy in the Treatment of Metastatic Brain Disease. R I Med J (2013) 2017;100:21-4.

7. Ghiassi-Nejad Z, Sindhu KK, Moshier E, et al. Factors associated with the receipt and completion of whole brain radiation therapy among older adults in the United States from 2010-2013. J Geriatr Oncol 2020;11:1096-102.

8. Tsao MN, Xu W, Wong RK, et al. Whole brain radiotherapy for the treatment of newly diagnosed multiple brain metastases. Cochrane Database Syst Rev 2018;1:CD003869.

9. Fairchild A, Harris K, Barnes E, et al. Palliative thoracic radiotherapy for lung cancer: a systematic review. J Clin Oncol 2008;26:4001-11.

10. Chow E, Zeng L, Salvo N, et al. Update on the systematic review of palliative radiotherapy trials for bone metastases. Clin Oncol (R Coll Radiol) 2012;24:112-24.

11. Cooke P, Sindhu KK, Lehrer EJ, et al. Palliating

Cite this article as: Sindhu KK, Lehrer EJ, Dharmarajan KV. Identifying areas of emphasis for future palliative radiation therapy curricula via an examination of theMednet. Ann Palliat Med 2021;10(7):7370-7377. doi: 10.21037/apm-21-956
Symptoms in Patients With Hepatocellular Carcinoma Involving the Inferior Vena Cava With External Beam Radiation Therapy. Cureus 2021;13:e14107.

12. Wei RL, Colbert LE, Jones J, et al. Palliative care and palliative radiation therapy education in radiation oncology: A survey of US radiation oncology program directors. Pract Radiat Oncol 2017;7:234-40.

13. Housri N. What is the overall goal of theMednet? 2013. Available online: https://www.themednet.org/question/246

14. Housri N. How is theMednet different from other online communities? 2018. Available online: https://www. themednet.org/question/2857

15. Housri N. Who is on theMednet? 2019. Available online: https://www.themednet.org/question/2856

16. Kalra M, Karuturi MS, Jankowitz RC, et al. Dissemination of breast cancer knowledge and expertise from NCI-CCC tumor boards with community oncologists. J Clin Oncol 2018;36:e18575.

17. Housri N, Ye JC, Lucas JT, et al. Sharing Experiential Knowledge and Clinical Evidence in an Online Radiation Oncology Social Network. Int J Radiat Oncol Biol Phys 2016;96:E417.

18. Bejjani A, Burt L, Washington C, et al. Using a Collaborative, Virtual Discussion Platform to Mobilize Oncologic Expertise for the COVID-19 Pandemic. JCO Clin Cancer Inform 2020;4:794-8.

19. Housri N, Burt L, Lucas JT, et al. Will academic and community physicians engage and share knowledge in an online physician social network? Lessons from the Radiation Oncology Community. J Clin Oncol 2016;34:e18200.

20. McCloskey SA, Tao ML, Rose CM, et al. National survey of perspectives of palliative radiation therapy: role, barriers, and needs. Cancer J 2007;13:130-7.

21. Wei RL, Mattes MD, Yu J, et al. Attitudes of radiation oncologists toward palliative and supportive care in the United States: Report on national membership survey by the American Society for Radiation Oncology (ASTRO). Pract Radiat Oncol 2017;7:113-9. 